\title{
Two-port vs. conventional (three-port) laparoscopic appendicectomy: a new technique in laparoscopic appendicectomy
}

\author{
Hemant P. Mhatre*, Vijay B. Kanake, Vipul V. Nandu
}

Department of General Surgery, Shri V. N. Govt. Medical College \& Hospital, Yavatmal, Maharashtra, India

Received: 15 September 2015

Accepted: 01 October 2015

\section{*Correspondence:}

Dr. Hemant P. Mhatre

E-mail: hemantmhatre546@gmail.com

Copyright: (c) the author(s), publisher and licensee Medip Academy. This is an open-access article distributed under the terms of the Creative Commons Attribution Non-Commercial License, which permits unrestricted non-commercial use, distribution, and reproduction in any medium, provided the original work is properly cited.

\begin{abstract}
Background: Three-port laparoscopic appendicectomy has proven its worth in the management of appendicitis. From a cosmesis, the umbilical and suprapubic portsites are hidden by natural camouflages, the Right Iliac Fossa (RIF) port is the only visible external sign of surgery. The two-port technique avoids even this marker of abdominal invasion.

Methods: 58 patients were studied for this study. Data was collected prospectively. The two port appendicectomy was performed with $10 \mathrm{~mm}$ umbilical working port and $5 \mathrm{~mm}$ supra-pubic camera port. A stitch was taken transparietaly in RIF which was under camera guidance passed through the tip of appendix and held with suture to retract the appendix. The base was ligated with an intra-corporeal knot and appendix cut and delivered out. Three port appendicectomy was performed via the $10 \mathrm{~mm}$ umbilical, $5 \mathrm{~mm}$ supra-pubic and $5 \mathrm{~mm}$ right iliac fossa ports. The appendicular stump was ligated with an endoloop or an intra-corporeal knot, appendix cut and delivered out

Results: 58 patients underwent surgery over the one year period for appendicitis. Out of 26 cases attempted, the two port appendicectomy was successful in 21 cases, with conversion to the three-port technique in 4 and conversion to open in 1 case. The complication rates, return to work were comparable between the two groups. Duration of operation was more whereas length of hospital stay was less in two port appendicectomy group as compared to conventional laparoscopic group.

Conclusions: Patients who underwent two port appendicectomy had a cosmetically better appearing scar than compared to three port appendicectomy cases.
\end{abstract}

Keywords: Laparoscopic appendicectomy, Two-port appendicectomy, Two port vs. three port, Scar

\section{INTRODUCTION}

Appendicectomy is the most commonly performed intraabdominal operation. Semm ${ }^{1}$ first introduced the laparoscopic method for appendicectomy in the early 1980s. Since then Laparoscopic Appendicectomy (LA) was made popular by various surgeons and preferred over the open method due to its inherent advantages. ${ }^{2}$ Over the past decade, the outcomes of laparoscopic appendectomies have compared favorably to those for open appendectomies because of decreased pain, fewer postoperative complications, shorter hospitalization, earlier mobilization, earlier return to work, and better cosmesis. ${ }^{3-5}$ However, despite these advantages, efforts are still being made to decrease abdominal incision and visible scars after laparoscopy. Recent research has led to the development of Natural Orifice Transluminal Endoscopic Surgery (NOTES). However, there are numerous difficulties that need to be overcome before a wider clinical application of NOTES is adopted, including complications such as the opening of hollow viscera, failed sutures, a lack of fully developed instrumentation; and the necessity of reliable cost-benefit 
analyses. ${ }^{6,7}$ The technique we have described is virtually scarless as the intra-abdominal entry points are hidden within natural camouflages. This technique replicates the operative technique of conventional laparoscopic appendicectomy and is hence associated with a very short learning curve as compared to the newer modalities with no extra need for expensive specialized equipment. Ours is an initial study to assess the practicality of two-port laparoscopic appendicectomy and to compare the results with the conventional three-port laparoscopic appendicectomy.

\section{METHODS}

The present study was conducted from June 2014 to May 2015 , in the patients of appendicitis admitted in surgery ward at the Shri Vasantrao Naik Government Medical College and hospital, Yavatmal, after the approval from the ethical committee of the above institute and with legal consent of patients.

Patient selection: A total of 58 cases of appendicitis were selected for this study of which 26 underwent two port appendicectomy and 32 underwent conventional three port appendicectomy. All the patients with age group of 14 to 50 years presenting with symptoms of appendicitis and diagnosed to have appendicitis without any known complications of appendicitis on sonography, were selected for study. Patients with the ASA $>2$, shock on admission, peritonitis, suspected perforated appendicitis, appendicular lump or peri-appendiceal abscess, cirrhosis, coagulation disorders and pregnancy were excluded from the study sample. They were all admitted and treated as in patients.

Operative details: Detailed clinical history of each patient was taken. All patients were subjected to thorough clinical examination. Baseline preoperative investigations were done for all patients. USG Abdomen and Pelvis was done and appendix size and location were determined. Each of these patients were subjected to laparoscopic appendicectomy with randomly selecting cases for two port and three port appendicectomy. Data were collected prospectively for the two port appendicectomy and three port appendicectomy. The two port appendicectomy was performed with one $10 \mathrm{~mm}$ umbilical working port and one $5 \mathrm{~mm}$ supra-pubic camera port. Under camera guidance appendix was identified (Figure 1) A stitch was taken transparietaly (Figure 2) in right iliac fossa which was under camera guidance passed through the tip of appendix and held with suture to retract the appendix (Figure 3). The appendicular artery was controlled with diathermy. The base was ligated with an intra-corporeal knot (Figure 4) and appendix cut and delivered out. Three port appendicectomy was performed via the conventional $10 \mathrm{~mm}$ umbilical, $5 \mathrm{~mm}$ supra-pubic and $5 \mathrm{~mm}$ right iliac fossa ports. Third port was used for Babcock's forceps to hold and retract the appendix. The appendicular stump was ligated with an endoloop or an intra-corporeal knot, appendix cut and delivered out.
The clinical outcomes of the two procedures were then compared. Statistical analysis was done with unpaired " $t$ " test to compare outcome in both cases. A P value $<0.05$ was considered to represent a statistically significant difference between groups.

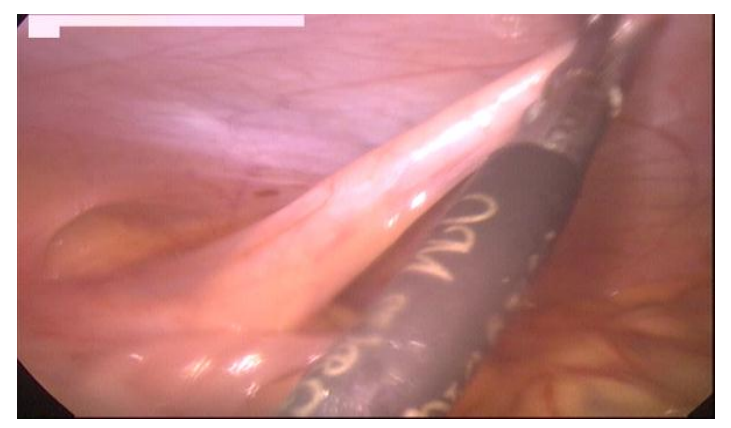

Figure 1: Showing inflamed edematous appendix.

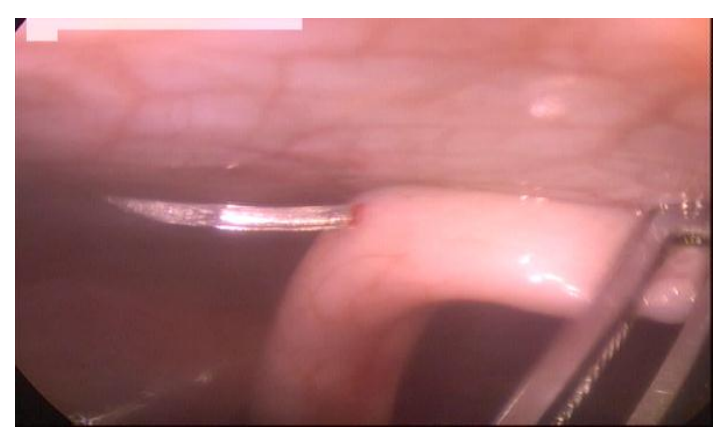

Figure 2: Showing tip of appendix pierced with needle with suture for retraction.

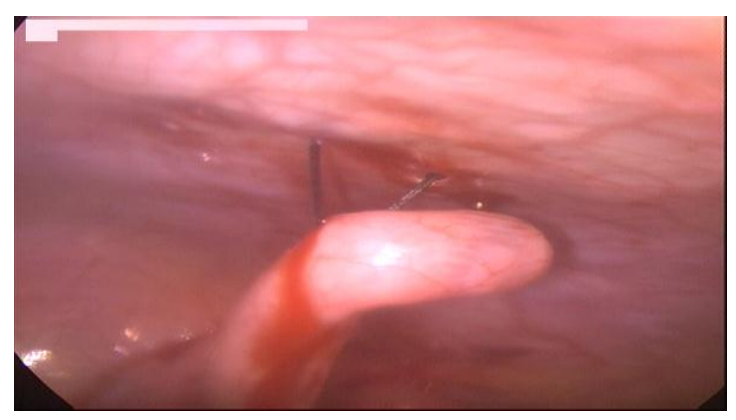

Figure 3: Appendix retracted and held with a suture.

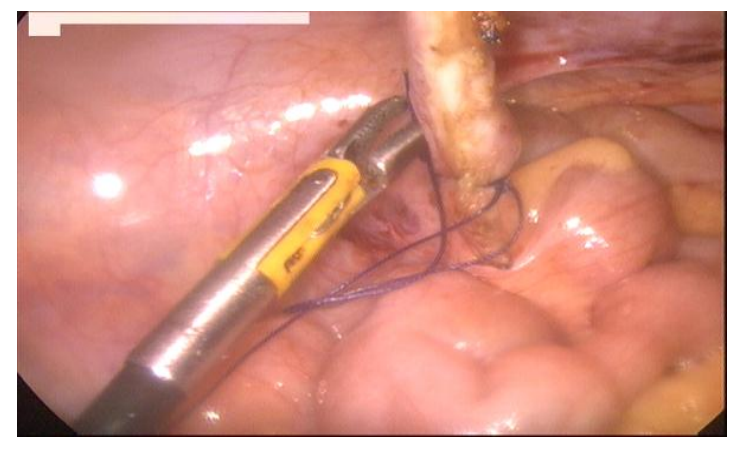

Figure 4: ligating the base of appendix by intracorporeal knotting with single operating port. 


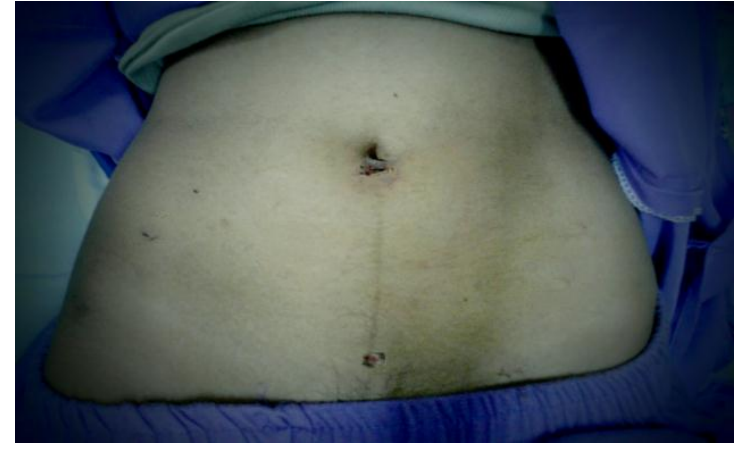

Figure 5: Post-operative scar photo after 10 days.

\section{RESULTS}

In our study, there were 58 patients. 26 of them were in the two port limb and 32 in the three port limb. Out of the
26 patients, 4 had to be converted to the Conventional laparoscopic method (defined as the insertion of one or more $5 \mathrm{~mm}$ ports). One case was converted to open procedure due to the presence of adhesions of inflammatory origin. The appendix was in the normal position in 32 patients and retro-caecal in 18 patients, right lumbar in 6 patients and sub-hepatic in 2 patients. The mean operative time was 29.8 minutes ranging from 20 to 45 minute. The mean hospital stay was 38.6 hours ranging from 32 to 50 hours. The two groups were well matched with respect to demographic information (age, sex and weight) (Table 1). There was no significant difference between the post-operative complications or return to work between of the two procedures, but the duration of operation was comparably more in two port appendicectomy group and length of hospital stay was significantly shorter in the two port appendicectomy group (Table 2).

Table 1: Details of patients.

\begin{tabular}{|llll|}
\hline & $\begin{array}{l}\text { Two port } \\
\text { appendicectomy }\end{array}$ & $\begin{array}{l}\text { Conventional three } \\
\text { port appendicectomy }\end{array}$ & P value \\
\hline Total no. of patients & 26 & 32 & N/A \\
\hline Female & 22 & 14 & N/A \\
\hline Male & 10 & 12 & N/A \\
\hline Duration or operation (min) & $29.8(20-45)$ & $24.5(20-34)$ & P $<0.05$ (significant) \\
\hline Extra port & Four patients & One patient & N/A \\
\hline Conversion to open procedure & One patient & One patient & N/A \\
\hline Intra-operative complications & Nil & Nil & Not Significant \\
\hline Postoperative complications & 1 & 2 & Not Significant \\
\hline $\begin{array}{l}\text { Duration of hospital stay } \\
\text { (hours) }\end{array}$ & $32.6(24-50)$ & $42.4(32-50)$ & P $<0.05$ (Significant) \\
\hline
\end{tabular}

Data are expressed as means (range) except where otherwise stated

Table 2: Statistical results.

\begin{tabular}{|llllllll|}
\hline & & Sig. & $\mathbf{t}$ & $\begin{array}{l}\text { Sig. } \\
(\text { 2-tailed) }\end{array}$ & Mean & $\begin{array}{l}\text { Std. } \\
\text { Deviation }\end{array}$ & $\begin{array}{l}\text { Std. Error } \\
\text { Mean }\end{array}$ \\
\hline $\begin{array}{l}\text { Duration of } \\
\text { hospital stay }\end{array}$ & 2 ports & 0.154 & -6.428 & $<0.005$ & 32.62 & 6.646 & 1.303 \\
\cline { 2 - 8 } & More ports & & -6.237 & $<0.005$ & 42.41 & 4.95 & 0.875 \\
\hline $\begin{array}{l}\text { Duration of } \\
\text { operation }\end{array}$ & 2 ports & 0.001 & 3.706 & $<0.005$ & 29.81 & 7.043 & 1.381 \\
\cline { 2 - 8 } & More ports & & 3.485 & $<0.005$ & 24.5 & 3.628 & 0.641 \\
\hline
\end{tabular}

\section{DISCUSSION}

Our study was conducted safely and showed no differences in clinical outcomes between patients treated by the two techniques apart from a shorter hospital stay in the group which had two port appendicectomy with better post-operative scar.

According to the Cochrane review and the EAES guidelines, there is a small but certain advantage of laparoscopic appendectomy over open appendectomy. ${ }^{8}$ Routinely, laparoscopic appendectomy is performed using three-ports. In our study, we have used two-port techniques as mentioned above. The mean operative time was 28.9 min, ${ }^{9-11}$ The average length of hospital stay was 38.6 hours in our study which compared favorably with other studies. ${ }^{9-11}$ Early discharge in our study was probably because patients had lesser pain but it was also likely due to a selection bias leading to a more favorable patient cohort in the Two port appendicectomy group as 
compared to the conventional laparoscopic appendicectomy group, but this also shows that the new technique is in no way inferior to the conventional method especially regarding the length of hospital stay.

In our study, the average duration of operation for two port appendicectomy group was 29.8 minutes compared to 24.5 minutes for conventional laparoscopic appendicectomy group. The increase in duration of operation was due to decreased number of hands to operate, as apart from camera port, only one port is left to work with and lack of practice to operate with single hand. With regular practice this extra time required will reduce to be comparable to conventional laparoscopic appendicectomy group.

In conventional laparoscopic appendicectomy group, the use of $5-10 \mathrm{~mm}$ ports in the umbilical and RIF, right hypochondrial or left iliac fossa regions often leave clearly visible scars. We have demonstrated that two port appendicectomy group using a suture retractor to replace the RIF trocar and the suprapubic trocar strategically placed below the hairline to be a safe and feasible procedure. It also has other advantages, even when inflammation is extensive, the ability to hold both the appendix and the mesoappendix at the same time with a loop retractor enables more stable manipulation and counter-traction than the use of conventional forceps and this procedure is also associated with less risk of causing an uncontrolled tear in the mesoappendix or an iatrogenic perforation of the appendix. Even though we have described the site of suture as RIF, flexibility in its placement is vital and best decided following an intraoperative view of the pathology. The suture can easily be sited elsewhere in the abdomen so as to ergonomically and cosmetically suit the pathology and the surgeon. If necessary, a surgeon can easily convert a two-port procedure to a conventional three-port procedure by adding another trocar. This allows the safety of the patient to be preserved. Our technique also eliminates one site of peritoneal invasion thereby reducing the chances of adhesions.

Many surgeons have attempted to reduce incisional morbidity and improve cosmetic outcomes in laparoscopic appendicectomy by using fewer and smaller ports. ${ }^{9-13}$ Kollmar et al. ${ }^{14}$ described moving laparoscopic incisions to hide them in the natural camouflages like the suprapubic hairline and improve cosmesis. Additionally, the reports in the literature indicate that minilaparoscopic appendectomies using 2-3 $\mathrm{mm}$ or even smaller instruments along with one $12-\mathrm{mm}$ port minimizes pain and improve cosmesis. ${ }^{12,15,16}$ More recently, studies by Ates et al. ${ }^{17}$ and Roberts et al. ${ }^{18}$ have described variants of an intracorporeal sling based singleport laparoscopic appendicectomy with good clinical results.

There is also an increasing trend towards Single Incision Laparoscopic Surgery (SILS) with use of a special multiport umbilical trocar. With SILS, there is a more conventional view of the field of surgery as compared NOTES. The equipment used for SILS is familiar to surgeons already doing laparoscopic surgery. Most importantly, it is easy to convert SILS to conventional laparoscopy by adding a few trocars, this conversion to conventional laparoscopy being called 'port rescue'. ${ }^{19}$ It has also been shown to be feasible, reasonably safe and cosmetically advantageous to standard laparoscopy. ${ }^{19,20}$ However, this newer technique involves specialized instruments and has a steep learning curve due to a loss of triangulation, clashing of instruments, crossing of instruments (cross triangulation), and a lack of maneuverability. ${ }^{19,20}$ There is also the additional problem of decreased exposure and an added financial burden of procuring special articulating or curved coaxial instruments. $^{20}$ SILS is still evolving, being used successfully in many a center, but with a significant way to go before it becomes mainstream. ${ }^{18}$ Thus limiting its wide spread use especially in rural/peripheral centers with limited resources. Our technique mimics the conventional laparoscopic appendicectomy technique and uses a suture to complete the procedure with the appendicular base being ligated extra-corporeally with a free tie. This reduces operative costs of an extra trocar and an endoscopic stapler or an endoloop.

\section{CONCLUSION}

We believe that this is a safe and feasible procedure, which while being cosmetically acceptable has an economic advantage and acts as an ideal bridge before SILS appendicectomy or even NOTES appendicectomy become standardized, affordable and widely accepted. One important advantage of the laparoscopic proceeding was the outstanding overview of the abdominal cavity with the possibility of more accurate diagnosis and proper decision-making. Two-port appendicectomy is a safe and effective alternative for the management of uncomplicated appendicitis. ${ }^{21}$ When compared with the three port technique the overall cost is less with two-port and it produces an even better cosmetic effect, due to the lesser number of punctures involved. However, the results cannot be generalized to overweight patients.

\section{Funding: No funding sources Conflict of interest: None declared \\ Ethical approval: The study was approved by the ethics committee of Shri Vasantrao Naik Government Medical College and hospital, Yavatmal}

\section{REFERENCES}

1. Semm K. Endoscopic appendectomy. Endoscopy. 1983;15(2):59-64.

2. Li X, Zhang J, Sang L, Zhang W, Chu Z, Li X, et al. Laparoscopic versus conventional appendectomy--a meta-analysis of randomized controlled trials. BMC Gastroenterol. 2010;10:129. 
3. Eypasch ESS, Lefering R, Neugenbauer EM. Laparoscopic versus open appendectomy: between evidence and common sense. Dig Surg. 2002;(19):518-22.

4. Yagnik VD, Rathod JB, Phatak AG. A retrospective study of two-port appendectomy and its comparison with open appendectomy and three-port appendectomy. Saudi J Gastroenterol. 2010;16(4):268-71.

5. Garbutt JM, Soper NJ, Shannon WD, Botero A, Littenberg B. Meta-analysis of randomized controlled trials comparing laparoscopic and open appendectomy. Surg Laparosc Endosc. 1999;9(1):17-26.

6. Chamberlain RS, Sakpal SV. A comprehensive review of single-incision laparoscopic surgery (SILS) and natural orifice transluminal endoscopic surgery (NOTES) techniques for cholecystectomy. J Gastrointest Surg. 2009;13(9):1733-40.

7. Romanelli JR, Earle DB. Single-port laparoscopic surgery: an overview. Surg Endosc. 2009;23(7):1419-27.

8. Sauerland S, Lefering R, Neugebauer EA. Laparoscopic versus open surgery for suspected appendicitis. Cochrane Database Syst Rev. 2004;(4):CD001546.

9. Sato N, Kojika M, Yaegashi Y, Suzuki Y, Kitamura M, Endo S, et al. Mini-laparoscopic appendectomy using a needle loop retractor offers optimal cosmetic results. Surg Endosc. 2004;18(11):1578-81.

10. Fazili FM, Al-Bouq Y, El-Hassan OM, Gaffar HF. Laparoscope-assisted appendectomy in adults: the two-trocar technique. Ann Saudi Med. 2006;26(2):100-4.

11. Valioulis I, Hameury F, Dahmani L, Levard G. Laparoscope-assisted appendectomy in children: the two-trocar technique. Eur J Pediatr Surg. 2001;11(6):391-4.
12. Gotz F, Pier A, Bacher C. Modified laparoscopic appendectomy in surgery. A report on 388 operations. Surg Endosc. 1990;4(1):6-9.

13. Meyer A, Preuss M, Roesler S, Lainka M, Omlor G. Transumbilical laparoscopic-assisted "one-trocar" appendectomy -- TULAA -- as an alternative operation method in the treatment of appendicitis. Zentralbl Chir. 2004;129(5):391-5.

14. Kollmar O, Z'graggen K, Schilling MK, Buchholz BM, Büchler MW. The suprapubic approach for laparoscopic appendectomy. Surg Endosc. 2002;16(3):504-8.

15. Matthews BD, Mostafa G, Harold KL, Kercher KW, Reardon PR, Heniford BT. Minilaparoscopic appendectomy. Surg Laparosc Endosc Percutan Tech. 2001;11(6):351-5.

16. Schier F. Laparoscopic appendectomy with 1.7-mm instruments. Pediatr Surg Int. 1998;14(1-2):142-3.

17. Ates O, Hakgüder G, Olguner M, Akgür FM. Single-port laparoscopic appendectomy conducted intracorporeally with the aid of a transabdominal sling suture. J Pediatr Surg. 2007;42(6):1071-4.

18. Roberts KE. True single-port appendectomy: first experience with the "puppeteer technique". Surg Endosc. 2009;23(8):1825-30.

19. Udwadia TE. Single-incision laparoscopic surgery: an overview. J Minim Access Surg. 2011;7(1):1-2.

20. Rao PP, Rao PP, Bhagwat S. Single-incision laparoscopic surgery - current status and controversies. J Minim Access Surg. 2011;7(1):616.

21. Konstadoulakis MM, Gomatos IP, Antonakis PT, Manouras A, Albanopoulos K, Nikiteas N, et al. Two-trocar laparoscopic-assisted appendectomy versus conventional laparoscopic appendectomy in patients with acute appendicitis. J Laparoendosc Adv Surg Tech A. 2006;16(1):27-32.

Cite this article as: Mhatre HP, Kanake VB, Nandu VV. Two-port vs. conventional (three-port) laparoscopic appendicectomy: a new technique in laparoscopic appendicectomy. Int J Sci Rep 2015;1(5):215-9. 